\title{
KEDUDUKAN SIGHAT TAQLIQ TALAQ DALAM HUKUM ISLAM
}

\author{
Zainal Abidin Muhja ${ }^{1}$
}

\section{Fakultas Hukum Universitas Borneo Tarakan}

\begin{abstract}
Weddings are performed by bond of trust, means that men and women who were married in the territory of the Republic of Indonesia shall have the religion together. The principle of the law of marriage is absolute means to not have a period of time dalaluarsa . Marriage must also be registered at the Office of Religious Affairs and registered atNote Civil. Marriage is an agreement between a man and a woman in the scope of family law. Marriage is a worship that will continue to take place up in heaven. By because it's every couple must keep the rope marriage that is not interrupted and canceled. Inamong those who cancel the marriage are divorce. Divorces according to Language is decided bond. As for the term fiqhi is decided bond of marriage with the pronouncement of talaq or that convey the same to the pronouncement of divorce. This study discusses "the effect of the Sighat Tak'lik agreement on the marriage bond in Sharia and its impact on divorce in religious courts in Tarakan City"
\end{abstract}

The research is aimed to know the result of treaty sighat Tak'lik and its impact on the divorce that happened in court Religion Tarakan City and knowing Forms agreement sighat Tak'lik who cancels wedding in sharia. The type of research that is used is the study of law Juridical Normative among others case approach, conceptual approach and statute approach. Case approach is the approach by way of doing research on the case - a case that relates to the issues that face.

Keywords: Sighat Taqliq, Talaq, Marriage , Marriage , Shariah

\section{PENDAHULUAN}

\section{A. Latar Belakang}

Manusia adalah mahluk sosial yang hidup secara berkelompok dan memiliki hak serta kewajiban. Manusia sebagai mahluk social juga memiliki peran sebagai individu yang menuntut pemenuhan kebutuhan batin dan lahiriahnya. Seorang Pria sebagai salah satu jenis mahluk hidup adalah mahluk yang diciptakan oleh Allah SWT untuk dapat membentuk keluarga yang sakinah mawaddah warahmah.

\footnotetext{
${ }^{1}$ Dosen Fakultas Hukum Universitas Borneo Tarakan, zainalabidinmuhja@gmail.com
} 
Tujuan hakiki seorang manusia hidup adalah untuk membentuk kelurga dan menghasilkan keturunan yang akan menjadi penerus warisan keluarga. Pria dan wanita memegang peranan yang berbeda dalam bingkai rumah tangga. Pria yang telah menikah artinya adalah pria yang mampu dan secara sadar membuat sebuah ikatan perkawinan dengan seorang wanita serta siap untuk memangku tanggung jawab sebagai seorang suami. Wanita yang telah menikah adalah wanita yang telah baligh dan berakal sehat terhadap setiap kewajibanya sebagai seorang istri dan ibu bagi anaknya kelak.

Konsep kehidupan pernikahan dibentuk pada saat Ijab dan qabul di ucapkan. Individu yang di kategorikan cakap dalam pernikahan, adalah individu yang cakap sesuai dengan Undang-Undang Pernikahan Nomor 1 Tahun 1974 menjelaskan Pria yang telah baligh, berakal sehat dan telah mencapai umur 18 Tahun dan wanita 16 Tahun. Perkawinan adalah ikatan lahir batin antara pria dan wanita dengan tujuan membentuk keluarga yang bahagia dan kekal berdasarkan Ketuhanan Yang Maha Esa².

Pernikahan yang dilakukan merupakan ikatan kepercayaan, artinya pria dan wanita yang menikah di Wilayah Negara Republik Indonesia wajib memiliki agama yang sama. Asas hukum perkawinan bersifat mutlak artinya tidak memiliki jangka waktu dalaluarsa. Perkawinan wajib pula didaftarkan di Kantor Urusan Agama dan tercatat di Catatan Sipil. Pernikahan adalah persetujuan antara seorang lelaki dan seorang perempuan dalam ruang lingkup hukum keluarga.

Kepastian hukum diperlukan untuk mencapai ketertiban dalam masyarakat, maka untuk itu diperlukan norma hukum atau peraturan sebagai pedoman dalam bertindak dan dapat memprediksikan apa yang akan terjadi bila melakukan perbuatan tertentu ${ }^{3}$

Perkawinan berakibat terhadap anak/keturunan dari perkawinan tersebut

\footnotetext{
2 Pemerintah Republik Indonesia, "Undang-Undang Republik Indonesia Nomor I Tahun 1974 Tentang Perkawinan," Mentri/Sekretaris Negara Republik Indonesia, 1974, https://doi.org/10.1098/rstb.1996.0056.
}

3 Trusto Subekti, "SAHNYA PERKAWINAN MENURUT UNDANG-UNDANG NOMOR 1 TAHUN 1974 TENTANG PERKAWINAN DITINJAU DARI HUKUM PERJANJIAN," Jurnal Dinamika Hukum, 2016, https://doi.org/10.20884/1.jdh.2010.10.3.103. Hlm 2 
tidak hanya itu perkawinan bahkan berakibat terhadap harta suami dan isteri dalam keluarga. Harta pernikahan dalam keluarga dapat dibagi dua yaitu harta Bersama dan harta bawaan. Pasal 35 Undang-Undang Pernikahan mengatur yaitu suami istri masing-masing mempunyai hak sepenuhnya terhadap harta bawaan untuk melakukan perbuatan hukum apapun. Harta Bersama membutuhkan persetujuan suami atau istri dalam melakukan perbuatan hukum terhadap harta Bersama.

Perkawianan dalam perdata didasarkan pada kesepakatan yang dilakukan oleh calon suami dan calon istri untuk saling menerima satu kepada lainya sebagai suami/istri. Hukum islam (Syariah) mengatur bahwa perkawinan dilakukan menurut ketentuan hukum fikh yaitu rukun perkawinan: Calon Suami Istri yang berjenis kelamin yang berbeda, Wali Nikah, Dua Orang Saksi Mahar dan Ijab-Qabul. Perkawinan tidak mengharuskan adanya pencatatan perkawinan dalam syariah.

Pasal 2 UU No.1 Tahun 1974 Perkawinan adalah sah apabila dilakukan menurut hukum masing-masing agamanya dan kepercayaanya itu. Sifat dari kewajiban ini adalah kumulatif dalam Syariah sedangkan dalam KUHPerdata sifatnya adalah alternative ${ }^{4}$.

Syariah mengatur mengenai perkawinan yang dilakukan oleh pemeluk yang berbeda yaitu: Islam melarang lelaki muslim kawin dengan perempuan non muslim (musryik) begitu juga islam tidak membolehkan perempuan muslim kawin dengan lelaki non muslim. Dasar utama agama islam bersifat universal artinya aturan ini berlaku untuk semua umat muslim yang ada di seluruh dunia "kawinilah perempuan atas dasar pertimbangan keyakinan agamanya.

KUHPerdata Pasal 7 ayat (2) Regeling op de Gemengde Huwelijken (GHR) atau Peraturan Perkawinan Campuran Stb. 1898 No. 158 dinyatakan bahwa "perbedaan agama, bangsa atau asal-usul" itu sama sekali tidak merupakan penghalang untuk melangsungkan perkawinan, jadiketentuan ini membuka seluas-luasnya kemungkinan untuk mengadakan perkawinan antar pemeluk

\footnotetext{
4 Pemerintah Republik Indonesia, “Undang-Undang Republik Indonesia Nomor I Tahun 1974 Tentang Perkawinan."
} 
agama yang berbeda, sekalipun dalam hal tertentu akan mengesampingkan ketentuan hukum agama. (Bandingkan dengan prinsip yang dikandung dalam Pasal 66 UU No. 1 Tahun 1974) ${ }^{5}$. Hal ini didasrkan pada konstitusi negara Indoneisa yaitu UUD NRI 1945 Pasal 29 Setiap warga negara dijamin kemerdekaanya untuk memeluk agama. 6

Berdasarkan data dari Sistem Informasi Penelurusan Perkara (SIPP) Kota Tarakan dari Tahun 2017-2018 tercatat 900 perkara perceraian yang diajukan sampai pada tanggal 18 Septembr 2017. Perkara cerai yang diajukan di Pengadilan Agama Kota Tarakan mayoritas adalah cerai gugat yaitu pihak istri yang melakukan gugatan cerai ${ }^{7}$.

Dari tiga hal di atas yang berkaitan dengan talak maka sighat ta'lik yang ada di buku pernikahan perlu dikaji kembali dari segi hukum Islam/Syariah.

\section{B. Rumusan Masalah}

Berdasarkan latar belakang diatas, maka rumusan permasalahan dalam usulan penelitian dosen pemula ini adalah:

1. Bagaimanakah akibat perjanjian Sighat Tak'lik terhadap ikatan pernikahan dalam Syariah dan dampaknya terhadap perceraian di pengadilan agama Kota Tarakan?

5 YURISPRUDENSI M.A.R.I. No. 382/Pdt/'89/PW/Jak.Pus.

Kptsn. M.A.R.I. No. 400/K/Pdt/'89/PW/Jak.Pus.

6 Pasal 7 ayat (2) Regeling op de Gemengde Huwelijken (GHR) atau Peraturan Perkawinan Campuran Stb. 1898 No. 158 dinyatakan bahwa "perbedaan agama, bangsa atau asal-usul" itu sama sekali tidak merupakan penghalang untuk melangsungkan perkawinan, jadiketentuan ini membuka seluas-luasnya kemungkinan untuk mengadakan perkawinan antar pemeluk agama yang berbeda, sekalipun dalam hal tertentu akan mengesampingkan ketentuan hukum agama. (Bandingkan dengan prinsip yang dikandung dalam Pasal 66 UU No. 1 Tahun 1974).

7 http://sipp.patarakan.net/list_perkara/page/45/MnNuSUxuUzhubWpBNUtHSIFGT0haMUc5TTR3UIVTRW9u a0tKRnhZZU9kM2paSFZzb1lIWlJIajQ3UnhSUm01clY2elFjVkgrbjZ1a0s1SWpkUTd2RFE9PQ==/ $\mathrm{key} / \mathrm{col} / 2$ 
2. Bagaimanakah bentuk perjanjian Sighat Tak'lik yang membatalkan pernikahan dalam syariah?

\section{Tujuan Penelitian}

Berkenaan dengan rumusan masalah diatas, penelitian dosen pemula ini bertujuan untuk:

1. Mengetahui akibat perjajian Sighat Tak'lik dan dampaknya terhadap perceraian yang terjadi di Pengadilan Agama Kota Tarakan.

2. mengetahui Bentuk perjanjian Sighat Tak'lik yang membatalkan pernikahan dalam syariah.

\section{TINJAUAN PUSTAKA}

\section{A. Pernikahan dan Asas-Asa Perkawinan Dalam Undang-Undang Nomor 1} Tahun 1974

Pernikahan adalah ikatan lahir batin antara pria dan wanita dengan tujuan membentuk keluarga yang bahagia dan kekal berdasarkan Ketuhanan Yang Maha Esa. KUHPerdata tidak memberikan definisi yang jelas terkait perkawinan dalam Pasal 26 Perkawinan adalah hubungan perdata (perjanjian) dengan tujuan hidup bersama dan perkawinan tersebut wajib didaftarakan sera diakui oleh negara. Hukum adat mendefinisikan perkawinan sebagai rite de passage atau dikenal dengan istilah tahapan dari lingkaran kehidupan.

Pernikahan/perkawinan secara etimologi yaitu asal usul katanya berasal dari Bahasa arab yang bermakna nikah atau zawaj. Hanabilah menjelaskan nikah adalah akad yang menggunakan lafaz nikah yang bermakna tajwiz dengan maksud mengambil manfaat untuk bersenang-senang8. Sajuti Thalib menjelaskan perkawinan adalah suatu perjanjian yang kuat dan kokoh untuk hidup bersama

${ }^{8}$ Abdurrahman Al-Jaziri, Kitab 'ala Mazahib Al-Arba'ah (Beirut Libanon: Dar Ihya Al-Turas AlArabi, 1986). 
secara sah antara seorang laki-laki dengan seorang perempuan membentuk keluarga yang kekal, santun menyantuni, kasih-mengasihi, tentram dan bahagia9 .

Rukun dan syarat menentukan suatu perbuatan hukum, terutama yang menyangkut dengan sah atau tidaknya perbuatan tersebut dari segi hukum. Kedua kata tersebut mengandung arti yang sama dalam hal bahwa keduanya merupakan sesuatu yang harus diadakan. Dalam suatu acara perkawinan rukun dan syaratnya tidak boleh tertinggal. Dalam arti perkawinan tidak sah bila keduanya tidak ada atau tidak lengkap.

Keduanya mengandung arti yang berbeda dari segi bahwa rukun itu adalah sesuatu yang berada di dalam hakikat dan merupakan bagian atau unsur yang mewujudkannya. Sedangkan syarat adalah sesuatu yang berada di luarnya dan tidak merupakan unsurnya. Syarat itu ada yang berkaitan dengan rukun dalam arti syarat yang berlaku untuk setiap unsur yang menjadi rukun. Ada pula syarat itu berdiri sendiri dalam arti tidak merupakan kriteria dari unsur-unsur rukun.

\section{B. Asas-Asas Hukum Perkawinan}

Asas monogami dalam pernikahan artinya seorang pria hanya dapat menikah dengan seorang wanita dalam sekali pernikahan konsep ini dikenal dengan istilah bilateral. Pernikahan juga hanya dapat dilakukan oleh oleh laki-laki dan perempuan yaitu jenis kelamin yang berbeda. Pernikahan di Negara Indonesia hanya dapat dilakukan oleh laki-laki dan perempuan yang memiliki agama yang sama tidak boleh berbeda.

Asas Kesepakatan adalah asas yang mengatur bahwa wajibya suatu kata yang diucapkan secara lisan oleh para pihak yaitu lelaki-dan perempuan dengan jelas serta tidak menimbulkan penafsiran ganda (ambigu) dalam pengucapannya ketika mengucapkan ijab dan qabul. Kesepakatan yang diberikan tidak boleh disebabkan karenan kekhilafan, paksaan, ataupun penipuan dalam bentuk

\footnotetext{
${ }^{9}$ Moh Idris Romulyo, Hukum Perkawinan Islam (Jakarta: Bumi Aksara, 1996).
} 
apapapun. Kesepakatan yang diberikan merupakan ucapan yang diberikan dengan berdasar kepada ibadah kepada Allah SWT untuk menciptakan kehidupan yang harmonis dengan landasan cinda dan kasih

Kehidupan pernikahan adalah kehidupan yang kekal tidak untuk sesaat (kontinuitas) serta tidak memiliki dalaluarsa. Oleh karena itu keluarga merupakan kesatuan kemasyarakatan yang terkecil. Keluarga adalah suatu organisasi yang didasarkan kepada penyatuan harta bersama. Asas ini adalah asas yang menjelaskan kesepakatan dalam arti para pihak telah menyampaikan kehendak masing-masing dan diterima dengan beritikad baik oleh para pihak. Asas ini sangat penting karena perjanjian telah dianggap sah dan mengikat kedua belah pihak setelah adanya kata sepakat. Kata sepakat wajib hukumnya diberikan secara sukarela tanpa adanya paksaan fisik maupun non fisik (dwang), khilaf (dwaling), dan penipuan (Bedrog).

Untuk menandakan kesepakatan tersebut dilakukan secara sukarela maka harus ditunjukan dalam ungkapan (sigah) Ijab dan Kabul. Ijab adalah pernyataan (baik melalui perkataan maupun perbuatan) untuk melaksanakan sesuatu Transaksi/Akad.

Persetujuan tidak hanya mengikat apa yang dengan tegas ditentukan didalamnya, melainkan juga segala sesuatu yang menurut sifat persetujuan dituntut berdasarkan keadilan, kebiasaan, atau undang-undang, dalam hal ini adalah prinsip kesamaan di dalam hukum bahwa para pihak memiliki hak yang menjadi kewajiban bagi pihak lain serta menetapkan standar perjanjian berdasarkan prinsip hak asasi manusia.

Pada pasal 1335 dan pasal 1336 KUHPerdata dijelaskan bahwa dalam persetujuan tanpa sebab, atau dibuat berdasarkan suatu sebab yang palsu atau yang terlarang, tidaklah mempunyai kekuatan dan apabila memang tidak ada dinyatakan suatu sebab, tetapi memang ada suatu sebab yang tidak terlarang, atau jika ada sebab lain yang tidak terlarang selain dan yang dinyatakan itu, persetujuan itu adalah sah. 
Sebab yang terlarang, jika sebab itu dilarang oleh undang-undang atau bila sebab itu bertentangan dengan kesusilaan atau dengan ketertiban umum. Persetujuan itu harus dinyatakan dengan tegas dan jelas sehingga tidak diperkenankan menyimpang dari padanya dengan jalan penafsiran.

Asas mengikat sebagai Undang-Undang (Pacta Sunt Servanda) Perjanjian yang dibuat secara sah mengikat kedua belah pihak seperti mengikatnya sebuah undang-undang (pasal 1338 KUHPerdata)

Asas Itikad Baik (good Faith) Pasal 1338 KUHPerdata ayat 3 menjelaskan bahwa Setiap perjanjian harus dilaksanakan dengan itikad baik. Balck Law Dictonary memberikan pengertian itikad baik adalah: "in or with good faith; honestly, openly, and sincerely; without deceit or fraud. Trully; Actually; without simulation or pretense".10

Asas Itikad Baik menurut Prof. Subekti, S.H "Itikad baik diwaktu membuat suatu perjanjian berarti kejujuran. Orang yang beritikad menaruh kepercayaan sepenuhnya kepada pihak lawan, yang dianggapnya jujur dan tidak menyembunyikan sesuatu yang buruk yang dikemudiannhari dapat menimbulkan kesulitan-kesulitan".

Asas itikad baik apabila disimpulkan: itikad baik adalah suatu sikap batin atau keadaan kejiwaan manusia yang: ${ }^{11}$

- Jujur

- $\quad$ Terbuka (tidak ada yang disembunyikan atau digelapkan

- $\quad$ Tulus ikhlas sungguh-sungguh

${ }^{10}$ Alexander Hamilton Frey and Henry Campbell Black, "Black's Law Dictionary," University of Pennsylvania Law Review and American Law Register, 2006, https://doi.org/10.2307/3308065.

${ }^{11}$ Nasrulloh Ali Munif, "ANALISIS AKAD IJARAH MUNTAHIYABITTAMLIK DALAM PERSPEKTIF HUKUM ISLAM DAN HUKUM POSITIF DI INDONESIA," An-Nisbah: Jurnal Ekonomi Syariah, 2018, https://doi.org/10.21274/an.2017.3.2.255-275. 
Fungsi itikad baik dalam perjanjian:

Rumusan pasal 1338 Ayat 3 KUHPerdata, dapat disimpulkan bahwa itikad baik harus digunakan pada saat pelaksanaan suatu perjanjian. Hal ini berarti bahwa pada waktu perjanjian dilaksanakan, selain ketentuan-ketentuan yang telah disepakati dalam perjanjian yang wajib ditaati oleh para pihak, melainkan juga itikad baik sebagai ketentuan-ketentuan yang tidak tertulis Itikad baik berfungsi menambah (aanvullend) ketentuan-ketentuan yang telah disepakati oleh kedua belah pihak didalam perjanjian

\section{METODE PENELITIAN}

\section{A. Metode Penelitian}

\section{a. Tipe Penelitian}

Tipe Penelitian yang digunakan adalah penelitian hukum Yuridis Normatif. Terkait dengan penelitian hukum ini, norma-norma hukum yang menjadi bahan kajian peraturan perundang-undangan, Kompilasi hukum Islam, Hadist, Sunnah, Kitab Agama dan KUHPerdata

\section{b. Pendekatan Masalah}

Sehubungan dengan tipe penelitian yang digunakan yakni Yuridis Normatif, antara lain case approach, conseptual approach dan statute approach. Case approach yaitu pendekatan dengan cara melakukan telaah terhadap kasus- kasus yang berkaitan dengan isu yang dihadapi. Conseptual approach yaitu pendekatan melalui pendapat-pendapat para sarjana yang dituangkan dalam konsep-konsep sebagai landasan pendukung, sedangkan statute approach yaitu pendekatan yang dilakukan dengan menelaah semua undang-undang dan regulasi yang menyangkut isu hukum ${ }^{12}$

\footnotetext{
12 Peter Mahmud Marzuki, Penelitian Hukum, Cetakan Keempat, Kencana Prenada Media Group,
} 


\section{c. Data Penelitian}

Jenis data yang digunakan dalam penelitian ini adalah data primer dan sekunder. Data primer adalah data kepustakaan, sedangkan data sekunder ialah data lapangan sebagai data pendukung keterangan atau menunjang kelengkapan data primer. Sumner data dalam penelitian ini adalah:

1. Data primer : data yang diperoleh dari bagian sengketa terkait perjanjian kawin di Pengadilan Agama Kota Tarakan dalam bentuk wawancara, observasi langsung, dan sumber berupa data tertulis:

1) Bahan Hukum Primer adalah bahan hukum yang sifatnya mengikat berupa peraturan perundang-undangan yang berlaku dan ada kaitannya

a) Undang-Undang Dasar Negara Republik Indonesia Tahun 1945

b) Undang-Undang Nomor 1 Tahun 1974

c) Al-Qur 'an Nur Karim tmengenai pernikahan, harta bersama, dan perjanjian nikah

d) YURISPRUDENSI M.A.R.I. No. 382 /Pdt/'89/PW/Jak.Pus. Kptsn. M.A.R.I. No. $400 / \mathrm{K} / \mathrm{Pdt} /$ ' 89 / PW/Jak.Pus

e) KUHPerdata (Bulgeriwetbook)

2) Bahan hukum sekunder yaitu bahan hukum yang bersifat menjelaskan terhadap bahan hukum primer berupa literatur, jurnal serta hasil penelitian terdahulu;

3) Bahan hukum terseier yaitu bahan hukum yang memberikan penjelasan terhadap bahan hukum primer dan sekunder berupa 
kamus, berita, majalah dan surat kabar.

\section{d. Prosedur Pengumpulan Bahan Hukum}

Baik data primer maupun data sekunder dikumpulkan berdasarkan topik permasalahan yang telah dirumuskan dan diklasifikasikan menurut sumber dan hierarkinya untuk dikaji secara komprehensif.

\section{e. Metode Analisis Data}

Berdasarkan bahan hukum yang diperoleh, maka penulisan Penelitian ini menggunakan metode deskriptif analisis, yaitu data yang dipergunakan adalah pendekatan kualitatif terhadap data primer dan data sekunder. Deskriptif tersebut meliputi isi. Struktur hukum positif yaitu suatu kegiatan yang dilakukan oleh penulis untuk menentukan isi aturan hukum yang dijadikan

rujukan dalam penyelesaian permasalahan hukum yang menjadi obyek kajian.

\section{PEMBAHASAN}

\section{Talak dalam Syariah}

Pernikahan adalah suatu ibadah yang akan terus berlangsung sampai di Syurga. Oleh karena itu setiap pasangan harus menjaga tali pernikahannya agar tidak terputus dan batal. Di antara yang membatalkan pernikahan adalah talak. Talak menurut Bahasa adalah memutuskan ikatan. Adapun menurut istilah fiqhi adalah memutuskan ikatan pernikahan dengan menggunakan lafaz talak atau yang semakna dengan lafaz talak. Talak menurut islam memiliki beberapa hal yang perlu diperhatikan. Di antaranya:

1. Talak dianggap sah walaupun dalam keadaan bercanda.

Rasulullah Shallallaahu 'alaihi wa sallam bersabda yang maknanya: "Ada tiga hal yang seriusnya serius, dan bercandanya dianggap serius, yaitu : nikah, 
cerai, dan rujuk" (Hadits riwayat at-Tirmidzi) ${ }^{13}$.

Berdasarkan hadits di atas maka talak dianggap jatuh walaupun dalam keadaan bercanda.

2. Talak ada yang sharih (jelas) dan ada juga kinayah (sindiran) ${ }^{14}$.

Talak yang jelas tidak perlu memerlukan kepada niat. Selama kata yang diucapkan memiliki arti talak atau cerai secara jelas maka talaq dianggap jatuh walaupun seseorang tidak dianggap berniat untuk menjatuhkan talak. Selama orang tersebut dalam keadaan sadar ketika mengucapkannya maka dianggap sah talak tersebut. Ada juga talak kinayah (sindiran). Talak sindiran ini dianggap jatuh jika seseorang yang mengucapkannya berniat untuk menjatuhkan talak. Seperti ucapan suami kepada istrinya: "Pulanglah engkau ke rumah orang tuamu" maka ucapan ini dianggap talak jika suami berniat dengan ucapan tersebut adalah talak. Jika suami tidak berniat talak maka tidak dianggap sebagai talak. Seperti suami tersebut ada dinas luar sehingga istrinya mesti dipulangkan ke orang tuanya dahulu.

3. Tidak ada perbedaan antara talak yang disyaratkan (mu'allaqan) dan yang tidak disyaratkan (munajjazan)

Talak dianggap sah baik yang mengucapkan talaq tersebut mensyaratkan sesuatu untuk jatuhnya talak atau tidak mensyaratkan sesusatu. Contoh talak yang disyaratkan dengan sesuatu adalah ucapan suami kepada istri: "Engkau tertalak jika pergi ke Mall". Kapan istri tersebut pergi ke mall maka talak dianggap sah.

\section{Pihak-Pihak yang dilarang untuk melangsungkan Pernikahan}

Perkawinan adalah hal penting dalam kehidupan seorang manusia tetapi ada pula berbagai hal yang membuat seseorang tidak dapat melangsungkan

${ }^{13}$ A Tirmidzi, Kitab Al-Jami, 892.

${ }^{14}$ Abdullah, Kitab Bughyatuthalib, II, 2008. 
perkawinan.

1. Antara keluarga sedarah garis keatas, kebawah, dan menyamping

Nikah dengan Wanita-Wanita yang diharamkan karena senasab atau hubungan kekeluargaan karena pernikahan berdasarkan firman Allah SWT dalam Surah An-Nisaa’:23 “ “:diharamkan atas kamu (menikahi) ibu-ibumu, anak-anak perempuanmu, saudara-saudara perempuanmu, saudara-saudara perempuan ayahmu, saudara-saudara perempuan ibumu, anak-anak perempuan dari saudara laki-lakimu, anak-anak perempuan dari saudara perempuan-perempuanmu, ibu-ibu yang mnyesuimu, saudara-saudara perempuan yang satu susuan denganmu, ibu-ibu isterimu (mertua), anak-anak perempuan dari istrimu (anak tiri) yang dalam pemeliharaanmu dari istri yang telah kamu campuri, tetapi jika belum mencampurinya (dan sudah kamu ceraikan) maka tidak berdosa atasmu (jika menikahinya). (dan diharamkan bagimu) istri-istri anak kandungmu (menantu), dan diharamkan mengumpulkan (dalam pernikahan) dua perempuan yang bersaudara kecuali yang terjadi pada masa lampau. Sungguh, Allah Maha Pengampun, Maha Penyanyang. 15

2. Nikah Mut'ah

Nikah mut'ah adalah suatu pernikahan yang bersifat sementara artinya memiliki jangka waktu masa pernikahan. Para ulama telah sepakat bahwa nikah ini adalah nikah yang terlarangserta tidak sah. Nikah mut'ah apabila di lakukan maka dikategorikan sebagai nikah yang dapat dibatalkan.

Hadits Shahih diriwayatkan oleh Muslim (No. 1406 (21)), dari sahabat Sabrah Al-Juhani radiyallaahu 'anhu16 "Wahai sekalian Manusia ! sesungguhnya aku pernah mengijinkan kalian untuk bersenang-senang dengan wanita (nikah mut'ah selama tiga hari). Dan sesungguhnya Allah telah mengharamkan hal tersebut (Nikah Mut’ah)

${ }^{15}$ Al-Quran, "The Holy Quran: Arabic Text and English Translation," Holy Quran, 2004. [AnNisaa; 23]

16 Muslim, Al Wajiz, Mausuu'ah Al-Fiqhiyyah, 1406th ed., n.d. 
selama-lamanya hingga hari kiamat.

3. Nikah dalam Masa Iddah

Surah Al-Baqarah :235 “Dan janganlah kamu menetapkan akad nikah, sebelum habis masa 'iddahnya"17

4. Nikah dengan wanita Non Muslim (Kafir)

"Dan janganlah kamu nikahi perempuan musyrik, sebelum mereka beriman. Sungguh hamba sahaya perempuan yang beriman lebih baik daripada perempuan musyrik meskipun ia menarik hatimu. Dan janganlah kamu nikahkan orang (Laki-Laki) musyrik (dengan perempuan yang beriman) sebelum mereka beriman. Sungguh hamba sahaya laki-laki yang beriman lebih baik daripada laki-laki musyrik meskipun ia menarik hatimu. Mereka mengajak ke neraka, sedangkan ALLAH mengajak ke surge dan ampunan dengan izin-Nya. (Allah) menerangkan ayat-ayat-Nya kepada manusia agar mereka mengambil pelajaran. (Al-Baqarah :221) ${ }^{18}$

5. Nikah dengan istri yang telah mendapatkan talak tiga. Diharamkan bagi seorang suami yang telah menalak istrinya yaitu talak tiga untuk dinikahinya kembali sebelumwanita tersebut menikah dengan orang lain dengan wajar lalu terjadi cerai antara keduanya maka suami sebelumnya boleh untuk menikahi wanita itu kembalisetelah masa iddahnya selesai. (Al-Baqarah :230)

6. Nikah pada saat melaksanakan ibadah ihram

Tidak boleh menikah ataupun melamar seseorang ketika sedang ihram

7. Nikah Dengan wanita yang masih bersuami ini sebagaimana dijelaskan dalam surah [An-Nisaa' :24]: “Dan (diharamkan juga kamu menikahi) perempuan yang bersuami..."

8. Nikah dengan wanita Pezina/Pelacur

"Pezina laki-laki tidak boleh menikah kecuali dengan pezina perempuan, atau

${ }^{17}$ Al-Quran, "The Holy Quran: Arabic Text and English Translation." [Al-Baqarah; 235]

${ }^{18} \mathrm{Al}$-Quran. [Al; Baqarah 221] 
dengan perempuan musyrik; dan pezina perempuan tidak boleh menikah kecuali dengan pezina laki-laki atau dengan laki-laki musyrik; dan yang demikian itu diharamkan bagi orang-orang mukmin" [An-Nuur :3]

Namun apabila keduanya telah bertaubat dengan taubat yang nasuha yaitu tobat yang dilakukan bersama dengan perbuatan tidak melakukannya lagi serta memperbaiki akhlak ibadah mereka, maka orang tersebut boleh dinikahi

9. Nikah Dengan lebih dari empat wanita

“Dan jika kamu khawatir tidak akan mampu berlaku adil terhadap (hak-hak) perempuan yatim (bilamana kamu menikahinya) maka nikahilah perempuan (lain) yang kamu senangi; dua, tiga, atau empat...." [An-Nisaa' :3]

\section{A. Bahan Bacaan}

Abdullah. Kitab Bughyatuthalib. II., 2008.

Al-Jaziri, Abdurrahman. Kitab 'ala Mazahib Al-Arba'ah. Beirut Libanon: Dar Ihya AlTuras Al-Arabi, 1986.

Al-Quran. "The Holy Quran: Arabic Text and English Translation.” Holy Quran, 2004.

Frey, Alexander Hamilton, and Henry Campbell Black. "Black's Law Dictionary." University of Pennsylvania Law Review and American Law Register, 2006. https://doi.org/10.2307/3308065.

Idris Romulyo, Moh. Hukum Perkawinan Islam. Jakarta: Bumi Aksara, 1996.

Munif, Nasrulloh Ali. “ANALISIS AKAD IJARAH MUNTAHIYABITTAMLIK DALAM PERSPEKTIF HUKUM ISLAM DAN HUKUM POSITIF DI INDONESIA." An-Nisbah: Jurnal Ekonomi Syariah, 2018. https://doi.org/10.21274/an.2017.3.2.255-275.

Muslim. Al Wajiz, Mausuu'ah Al-Fiqhiyyah. 1406th ed., n.d.

Pemerintah Republik Indonesia. "Undang-Undang Republik Indonesia Nomor I Tahun 1974 Tentang Perkawinan." Mentri/Sekretaris Negara Republik Indonesia, 1974. https://doi.org/10.1098/rstb.1996.0056.

Subekti, Trusto. "SAHNYA PERKAWINAN MENURUT UNDANG-UNDANG NOMOR 1 TAHUN 1974 TENTANG PERKAWINAN DITINJAU DARI HUKUM PERJANJIAN." Jurnal Dinamika Hukum, 2016. https://doi.org/10.20884/1.jdh.2010.10.3.103. 
Tirmidzi, A. Kitab Al-Jami, 892.

Peter Mahmud Marzuki, 2008, Penelitian Hukum, Cetakan Keempat, Jakarta: Kencana Prenada Media Group, Edisi Kesatu.

\section{B. Peraturan Perundang-Undangan}

Undang-Undang Dasar Negara Republik Indonesia Tahun 1945.

Undang-Undang Nomor 1 Tahun 1974

Al-Qur 'an Nur Karim tmengenai pernikahan, harta bersama, dan perjanjian nikah YURISPRUDENSI M.A.R.I. No. 382/Pdt/'89/PW/Jak.Pus. Kptsn. M.A.R.I. No. 400/K/Pdt/'89/PW/Jak.Pus

KUHPerdata 